\title{
Pricing Convertible Bonds with Credit Risk under Regime Switching and Numerical Solutions
}

\author{
Wei-Guo Zhang and Ping-Kang Liao \\ School of Business Administration, South China University of Technology, Guangzhou 510640, China \\ Correspondence should be addressed to Wei-Guo Zhang; wgzhang@scut.edu.cn
}

Received 26 December 2013; Accepted 9 April 2014; Published 19 May 2014

Academic Editor: Fenghua Wen

Copyright ( 2014 W.-G. Zhang and P.-K. Liao. This is an open access article distributed under the Creative Commons Attribution License, which permits unrestricted use, distribution, and reproduction in any medium, provided the original work is properly cited.

This paper discusses the convertible bonds pricing problem with regime switching and credit risk in the convertible bond market. We derive a Black-Scholes-type partial differential equation of convertible bonds and propose a convertible bond pricing model with boundary conditions. We explore the impact of dilution effect and debt leverage on the value of the convertible bond and also give an adjustment method. Furthermore, we present two numerical solutions for the convertible bond pricing model and prove their consistency. Finally, the pricing results by comparing the finite difference method with the trinomial tree show that the strength of the effect of regime switching on the convertible bond depends on the generator matrix or the regime switching strength.

\section{Introduction}

Convertible bond is a kind of the most important financing instruments, so the convertible bond market occupies an important position in the international financial market. American convertible bond market is the largest market in the world, and it has issued more than 400 trillion dollars in total from 1980 to 2011. Hong Kong is an international financial center; there are about 70 trillion yuan of convertible bonds in 2012. Although the amount of convertible bonds issued in developing countries is much less than that in developed countries, the convertible bonds markets of some countries are developing rapidly. For example, China issued more than 60 trillion yuan of new convertible bonds in 2010, which is almost three times the level of four years ago. Because of the importance of the convertible bonds in the financial market, the convertible bond pricing problem is a hot topic.

Taking the corporate value as a basic variable, Ingersoll [1] constructed a structural model for pricing convertible bonds by deriving a Black-Scholes-type partial differential equation based on Black-Scholes' theory. Following the work of Ingersoll [1], Brennan and Schwartz [2] explored the valuation of the convertible bonds with dividends and callable provision. However, the structural approach has a shortcoming which is the fact that the data of the corporate value is difficult to measure and observe. To overcome this shortcoming, McConnell and Schwartz [3] firstly selected the stock price as the basic variable, which becomes a mainstream later. With further research, the clauses of convertible bond also are indepth studied. Kimura and Shinohara [4] and Yang et al. [5] explored the effect of reset clause on noncallable convertible bonds; they also derived an exact solution on the valuation of the convertible bonds with and without dilution effect. The numerical solutions are also adapted to price the convertible bonds. Brennan and Schwartz [6] took stochastic interest rate into account firstly and built the so-called two-factor model for convertible bond pricing that is popular since it is available. Then, a three-factor model was established by Davis and Lischka [7] to value the convertible bonds with stochastic credit risk. To solve the complex multifactor models, characteristics/finite elements and trinomial tree model are applied to the valuation of the convertible bonds such as Barone-Adesi et al. [8] and $\mathrm{Xu}$ [9]. Some other researches consider special convertible bonds or other factors of the convertible bonds. Yagi and Sawaki [10] proposed a valuation model of callable-puttable reverse convertible bonds, which are issued by a company to be exchanged for the shares of another company. Instead of the popular geometric 
Brownian motion model, Labuschagne and Offwood [11] valued the convertible bonds with the CGMY stock price process. Lee and Yang [12] presented the unexplained portion of the valuation model of convertible bonds based on MCDM.

Credit risk is another important factor that affects the value of convertible bonds. As early as the structural approach is available, the credit risk is considered by comparing the corporate value and the convertible bond value. However, this idea is not popular for the shortcoming of the structural approach. There are two main ways to deal with the credit risk in the pricing models now. One way measures the credit risk by the credit spread of bonds. McConnell and Schwartz [3] applied this idea to the valuation of the convertible bonds. Tsiveriotis and Fernandes [13] innovatively defined the "cash only part of the convertible bonds," whose discount rate contains credit spread and is different from the rest of the convertible bonds. This idea is also applied in binomial tree, trinomial tree, and multifactor model of the convertible bond pricing with credit risk, such as the work of Bardhan et al. [14]. The other way measures the credit risk by the default intensity. The default intensity to price convertible bonds with credit risk was introduced to measure the credit risk in the early work of Duffie and Singleton [15] and Takahashi et al. [16]. However, these works are not reasonable enough for they cannot measure the credit risk accurately so that they need to be improved. Thus, Ayache et al. [17] proposed a new model for the convertible bonds pricing with credit risk (AFV model). Different from previous work, they adopt default intensity to measure the credit risk and build a model by deriving the PDE of the convertible bonds. This idea is also introduced to trinomial tree and multifactor model, such as the work of Chambers and Liu [18]. Milanov et al. [19] set a binomial tree model for the valuation of convertible bond and prove that their model converges in continuous time to the AFV model.

Since the early 20th century, the global economy interchanges between the boom and the bust frequently. Similarly, the security market also interchanges between the "bull market" and the "bear market" frequently. The stock price processes have different characteristics in different states of economy. Considering the regime switching, some options pricing models with regime switching are proposed. The options pricing with regime switching can be traced back to the work of Naik [20], who establishes a formula of option pricing with only two states. Then, Buffington and Elliot [21] built pricing models of European options and American options with regime switching that the number of states is uncertain but finite. The valuation of exotic options was also studied by Boyle and Draviam [22] with finite difference method. Yuen and Yang [23] proposed a modified trinomial tree model to price complex options with regime switching. The valuation of the currency options with stochastic volatility and stochastic interest rate under regime switching was studied by Siu et al. [24] later. Goutte [25] considered general regime switching stochastic volatility models where both the asset and the volatility dynamics depend on the values of a Markov jump process and obtain pricing and hedging formulae by risk minimization approach. As a kind of medium-term or long-term securities, the value of the convertible bonds may be affected by the regime switching. The regime switching is also considered in the convertible bond pricing. Song et al. [26] developed a valuation model for a perpetual convertible bond by the valuation model for the perpetual American option. However, they do not take credit risk, dilution effect, and debt leverage into account, and the perpetual convertible is not the most common kind of convertible bond.

The value of the convertible bond is affected by credit risk, market environment, dilution, and so forth. As we know, the financial leverage of the corporate has also effect on the return of shareholders, which will affect the convertible bonds finally. This paper will discuss the pricing convertible bonds with credit risk under regime switching, which take the dilution effect and the debt leverage into account. The rest of this paper is organized as follows. Section 2 derives the BlackScholes-type partial differential equation of the convertible bonds and proposes the theoretical model. Section 3 considers the debt leverage and gives a modification of the historical volatility. Section 4 introduces main details of the numerical solutions and proves their consistency. Section 5 presents a numerical analysis for the features of the convertible bonds. Finally, the main conclusions are given in Section 6.

\section{Theoretical Model of the Convertible Bond Pricing}

In this section, we derive the Black-Scholes-type partial differential equation of the convertible bonds and try to build up the pricing model. Firstly, we give the dynamic process of the stock price $S$ and the process of the bond value $B$. Here we assume that the states of the economy are modeled by a continuous-time, finite-state, observable Markov chain $X=\left\{X_{t}: t \geq 0\right\}$ on a complete probability space $(\Omega, \mathscr{F}, \mathscr{P})$ with a finite-state space $\chi=\left\{e_{1}, e_{2}, \ldots, e_{L}\right\}$, where unit vector $e_{k}=(0, \ldots, 0,1,0, \ldots 0)^{\prime} \in \mathfrak{R}^{L}$ represents the $k$ th regime or the $k$ th state. Let $A=\left\{a_{i j}\right\}_{i, j=1,2, \ldots, L}$ be the generator matrix of the Markov chain $X$, which satisfies the following formula:

$$
\sum_{j=1}^{L} a_{i j}=0, \quad i=1,2, \ldots, L .
$$

Then, the semimartingale decomposition of continuous-time Markov chain $X$ is given by

$$
d X_{t}=A X_{t} d t+d M_{t}
$$

where $M=\left\{M_{t}: t \geq 0\right\}$ is an $\mathfrak{R}^{L}$-valued martingale.

Let $r=\left\{r_{t} \mid t \geq 0\right\}$ be the process of risk-free rate. In the market with regime switching, the risk-free rate only depends on the current state of the market, so the risk-free rate at time $t$ can be expressed by inner product form as

$$
r_{t}=r\left(X_{t}\right)=\left\langle\mathbf{r}, X_{t}\right\rangle
$$

where $\mathbf{r}=\left(r_{1}, r_{2}, \ldots, r_{L}\right) \in \mathfrak{R}^{L}$. Similarly, let $\mu=\left\{\mu_{t}: t \geq 0\right\}$, $q=\left\{q_{t}: t \geq 0\right\}$, and $\sigma=\left\{\sigma_{t}: t \geq 0\right\}$ be the appreciation rate, 
the continuous dividend rate, and the volatility of underlying stock, respectively. They can be expressed as

$$
\begin{gathered}
\mu_{t}=\mu\left(X_{t}\right)=\left\langle\boldsymbol{\mu}, X_{t}\right\rangle, \quad q_{t}=q\left(X_{t}\right)=\left\langle\mathbf{q}, X_{t}\right\rangle, \\
\sigma_{t}=\sigma\left(X_{t}\right)=\left\langle\boldsymbol{\sigma}, X_{t}\right\rangle .
\end{gathered}
$$

Here $\boldsymbol{\mu}=\left(\mu_{1}, \mu_{2}, \ldots, \mu_{L}\right) \in \mathfrak{R}^{L}, \mathbf{q}=\left(q_{1}, q_{2}, \ldots, q_{L}\right) \in \mathfrak{R}^{L}$, and $\boldsymbol{\sigma}=\left(\sigma_{1}, \sigma_{2}, \ldots, \sigma_{L}\right) \in \mathfrak{R}^{L}$.

Continuous process $B=\left\{B_{t}: t \geq 0\right\}$ denotes the process of bond value without risk as

$$
d B_{t}=r_{t} B_{t} d t
$$

Following the assumptions at the first of this part, the stock price process with initial value $S_{0}$ satisfies the equation

$$
d S_{t}=\left(\mu_{t}-q_{t}\right) S_{t} d t+\sigma_{t} S_{t} d W_{t},
$$

where $W=\left\{W_{t}\right\}_{t \in[0, T]}$ is a standard Brownian motion.

We consider a convertible bond with maturity $T$ and face value $F$. Without losing generality, we assume that the convertible bond has the following clauses. (1) The convertible bond pays a fixed coupon amount $c_{i}$ at time $t c_{i}(i=$ $1,2, \ldots, M)$. (2) The convertible bond can be converted to $\kappa$ share after time $T_{\text {con }}\left(0 \leq T_{\text {con }} \leq T\right)$. (3) The convertible bond is callable by the issuers at an interval price $B_{c}$ after time $T_{\text {call }}\left(T_{\text {con }} \leq T_{\text {call }} \leq T\right)$. (4) The convertible bond is puttable by the holders at a price $B_{p}$ after time $T_{\text {put }}\left(T_{\text {con }} \leq T_{\text {put }} \leq T\right)$. Let $V_{k}(k=1,2, \ldots, L)$ be the price of convertible bond at the $k$ th regime, and set $\mathbf{V}=\left(V_{1}, V_{2}, \ldots, V_{L}\right)$.

We now consider the valuation of the convertible bonds with credit risk under regime switching. When the company goes bankrupt, the holders of the convertible bonds can get some compensation, which is usually less than $F$. What is more, if all assets of the company are more valuable than all debt or the company is merged or reorganized, the stock of the company is still valuable. Therefore, we make the following assumptions.

(1) The default probability approximately is equal to $\lambda_{t} d t$ for $d t$, where $\lambda_{t}=\lambda\left(X_{t}\right)=\left\langle\lambda, X_{t}\right\rangle$ and $\lambda=$ $\left(\lambda_{1}, \lambda_{2}, \ldots, \lambda_{L}\right)$.

(2) Upon default, the holders can choose to receive the compensation $R_{t} F$ per convertible bond or convert to $\kappa\left(1-\eta_{t}\right)$ shares. Here $R_{t}=R\left(X_{t}\right)=\left\langle\mathbf{R}, X_{t}\right\rangle$ is the recovery factor and $\eta_{t}=\eta\left(X_{t}\right)=\left\langle\boldsymbol{\eta}, X_{t}\right\rangle$ is the jump ratio of underlying stock. Set $\mathbf{R}=\left(R_{1}, R_{2}, \ldots, R_{L}\right)$ and $\boldsymbol{\eta}=\left(\eta_{1}, \eta_{2}, \ldots, \eta_{L}\right)$.

In the following discussion, we try to establish the pricing model of convertible bonds by constructing a hedging portfolio based on no arbitrage principle. We assume that the hedging portfolio $\prod$ includes a convertible bond $V_{t}$ and $-\beta_{t}$ shares $S_{t}$ at time $t$. When there is no coupon payment in $[t, t+d t]$, the value of hedging portfolio at time $t$ is

$$
\prod_{t}=V_{t}-\beta_{t} S_{t} .
$$

Absent of default, the change in value of the hedging portfolio after time $d t$ is

$$
d V-\beta_{t} d S .
$$

Upon default, the loss of the hedging portfolio after time $d t$ is

$$
\begin{aligned}
& \left(V_{t}-\beta_{t} S_{t}\right)-\left(\max \left\{\kappa\left(1-\eta_{t}\right) S_{t}, R_{t} B\right\}-\beta_{t}\left(1-\eta_{t}\right) S_{t}\right) \\
& \quad=V_{t}-\beta_{t} \eta_{t} S_{t}-\max \left\{\kappa\left(1-\eta_{t}\right) S_{t}, R_{t} B\right\} .
\end{aligned}
$$

As the default probability is $\lambda_{t} d t$ and no default probability is $1-\lambda_{t} d t$ in time $d t$, the expected change in value of the hedging portfolio after time $d t$ is the weighted average of the hedging portfolio value change upon default and absent of default as

$$
\begin{aligned}
d \prod_{t}= & \left(1-\lambda_{t} d t\right)\left(d V-\beta_{t} d S\right) \\
& -\lambda_{t} d t\left(V_{t}-\beta_{t} \eta_{t} S_{t}-\max \left\{\kappa\left(1-\eta_{t}\right) S_{t}, R_{t} B\right\}\right) .
\end{aligned}
$$

Applying Ito formula with regime switching to (10), we have

$$
\begin{aligned}
d \prod_{t}= & {\left[\frac{\partial V}{\partial t}+\left(\mu_{t}-q_{t}\right) S_{t} \frac{\partial V}{\partial S}+\frac{1}{2} \sigma_{t}^{2} S_{t}^{2} \frac{\partial^{2} V}{\partial S^{2}}-\beta \mu_{t} S_{t}\right] d t } \\
& +\lambda_{t} d t\left(V_{t}-\beta_{t} \eta_{t} S_{t}\right)+\lambda_{t} d t \max \left\{\kappa\left(1-\eta_{t}\right) S_{t}, R_{t} B\right\} \\
& +\left(\mu_{t} S_{t} \frac{\partial V}{\partial S}-\beta_{t} \mu_{t} S_{t}\right) d W_{t}+\left\langle\mathbf{V}, d X_{t}\right\rangle .
\end{aligned}
$$

Following the no arbitrage principle, we have

$$
d \prod_{t}=r_{t} \prod_{t} d t
$$

That is,

$$
\begin{aligned}
r_{t}\left(V_{t}-\beta_{t} S_{t}\right) d t & \\
=[ & \frac{\partial V}{\partial t}+\left(\mu_{t}-q_{t}\right) S_{t} \frac{\partial V}{\partial S} \\
& +\frac{1}{2} \sigma_{t}^{2} S_{t}^{2} \frac{\partial^{2} V}{\partial S^{2}}-\beta \mu_{t} S_{t}+\lambda_{t}\left(V_{t}-\beta_{t} \eta_{t} S_{t}\right) \\
& \left.+\lambda_{t} \max \left\{\kappa\left(1-\eta_{t}\right) S_{t}, R_{t} B\right\}+\left\langle\mathbf{V}, A X_{t}\right\rangle\right] d t \\
& +\left(\mu_{t} S_{t} \frac{\partial V}{\partial S}-\beta_{t} \mu_{t} S_{t}\right) d W_{t}+\left\langle\mathbf{V}, d M_{t}\right\rangle .
\end{aligned}
$$

Similar to. Buffington and Elliot [21], all the terms in the right of (13) must be equal to the left of equation; that is

$$
\mu_{t} S_{t} \frac{\partial V}{\partial S}-\beta_{t} \mu_{t} S_{t}=0 \quad \text { or } \quad \frac{\partial V}{\partial S}=\beta_{t} .
$$

Consider

$$
\begin{aligned}
r_{t}\left(V_{t}\right. & \left.-\beta_{t} S_{t}\right) d t \\
= & \frac{\partial V}{\partial t}+\left(\mu_{t}-q_{t}\right) S_{t} \frac{\partial V}{\partial S} \\
& +\frac{1}{2} \sigma_{t}^{2} S_{t}^{2} \frac{\partial^{2} V}{\partial S^{2}}-\beta \mu_{t} S_{t}+\lambda_{t}\left(V_{t}-\beta_{t} \eta_{t} S_{t}\right) \\
& +\lambda_{t} \max \left\{\kappa\left(1-\eta_{t}\right) S_{t}, R_{t} B\right\}+\left\langle\mathbf{V}, A X_{t}\right\rangle .
\end{aligned}
$$


Substituting (14) into (15), we obtain

$$
\begin{aligned}
\frac{\partial V}{\partial t} & +\left(r_{t}-q_{t}+\lambda_{t} \eta_{t}\right) S_{t} \frac{\partial V}{\partial S} \\
& +\frac{1}{2} \sigma_{t}^{2} S_{t}^{2} \frac{\partial^{2} V}{\partial S^{2}}-\left(r_{t}+\lambda_{t}\right) V_{t}+\langle\mathbf{V}, A X\rangle \\
& +\lambda_{t} \max \left\{\kappa\left(1-\eta_{t}\right) S_{t}, R_{t} B\right\}=0 .
\end{aligned}
$$

Equation (16) is partial difference equation or the so-called Black-Scholes-type partial differential equation of the convertible bond price with credit risk under regime switching.

$$
\begin{aligned}
& r_{k}=\left\langle\mathbf{r}, e_{k}\right\rangle, \quad q_{k}=\left\langle\mathbf{q}, e_{k}\right\rangle, \quad \sigma_{k}=\left\langle\boldsymbol{\sigma}, e_{k}\right\rangle, \\
& \lambda_{k}=\left\langle\lambda, e_{k}\right\rangle, \quad \eta_{k}=\left\langle\boldsymbol{\eta}, e_{k}\right\rangle, \quad R_{k}=\left\langle\mathbf{R}, e_{k}\right\rangle, \\
& V_{k}=V_{k, t}=\left\langle\mathbf{V}, e_{k}\right\rangle, \quad k=1,2, \ldots, L .
\end{aligned}
$$

Equation (16) can be rewritten as

$$
\begin{gathered}
\frac{\partial V_{k}}{\partial t}+\left(r_{k}-q_{k}+\lambda_{k} \eta_{k}\right) S_{t} \frac{\partial V_{k}}{\partial S}+\frac{1}{2} \sigma_{k}^{2} S_{t}^{2} \frac{\partial^{2} V_{k}}{\partial S^{2}}-\left(r_{k}+\lambda_{k}\right) V_{k} \\
+\sum_{l=1}^{N} a_{k l} V_{l}+\lambda_{k} \max \left\{\kappa S_{t}\left(1-\eta_{k}\right), R_{k} B\right\}=0, \\
k=1,2, \ldots, L .
\end{gathered}
$$

We must notice that (18) is only applicable during two coupon payments. When the coupon payment is paid, the price per convertible bond will be reduced by the amount of coupon at once. Therefore, the price of the convertible bonds at time $t c_{i}$ satisfies

$$
V_{t c_{i}}^{+}=V_{t c_{i}}^{-}-c_{i}, \quad i=1,2, \ldots, M-1
$$

When all investors convert their convertible bonds, some liabilities become the owner's equity and the number of shares increases. We assume that the company issues $m$ stocks and $n$ convertible bonds. If all convertible bonds are converted at time $t$, owner's equity value is $m S_{t}+n F$ totally. As the number of stocks becomes $m+n \kappa$, the value per stock is $\left(m S_{t}+n F\right) /(m+n \kappa)$, which is less than $S_{t}$ when $S_{t}>F / \kappa$. This is the so-called dilution effect in convertible bonds. So the investor will get $\kappa\left(m S_{t}+n F\right) /(m+n \kappa)$ rather than $\kappa S_{t}$ per convertible bond when the convertible bonds are converted. Thus, the dilution effect can be adjusted by changing the payment of the convertible bonds.

A rational investor seeks to maximize the value of the convertible bond at any time. The value of a convertible bond must be greater than or equal to its conversion value during the conversion time. Thus, we get the conversion provision:

$$
V_{k, t} \geq \frac{\left(m S_{t}+n F\right) \kappa}{m+n \kappa}, \quad t \in\left[T_{\text {con }}, T\right]
$$

At last time $T$, the company will give a return which is more than or equal to face return to call the convertible bonds. Thus, at time $T$, the value of convertible bonds must be

$$
V_{k, T}=\max \left\{\frac{\left(m S_{T}+n B\right) \kappa}{m+n \kappa}, F+c_{M}\right\} .
$$

Thus, we get the terminal condition of the partial difference equation (18). If the convertible bonds are puttable at time $t$, the investor can get at least $B_{p}$ for par convertible bond. Thus, we get the put provision as

$$
V_{k, t} \geq B_{p}, \quad t \in\left[T_{\text {put }}, T\right] .
$$

Similarly, the value of a convertible bond must be less than the maximum of conversion value and $B_{c}$ when the convertible bonds are callable at time $t$, or the convertible bonds will be called by the company. This call provision can be written as

$$
V_{k, t} \leq \max \left\{\frac{\left(m S_{t}+n F\right) \kappa}{m+n \kappa}, B_{c}\right\}, \quad t \in\left[T_{\text {call }}, T\right] .
$$

Considering constraints of the convertible bonds including conversion provision, put provision, and call provision, we get the pricing model of convertible bonds with credit risk under regime switching as follows:

$$
\begin{aligned}
\frac{\partial V_{k}}{\partial t} & +\left(r_{k}-q_{k}+\lambda_{k} \eta_{k}\right) S_{t} \frac{\partial V_{k}}{\partial S} \\
& +\frac{1}{2} \sigma_{k}^{2} S_{t}^{2} \frac{\partial^{2} V_{k}}{\partial S^{2}}-\left(r_{k}+\lambda_{k}\right) V_{k}+\sum_{l=1}^{N} a_{k l} V_{l} \\
& +\lambda_{k} \max \left\{\kappa S_{t}\left(1-\eta_{k}\right), R_{k} F\right\}=0 \\
V_{k, T} & =\max \left\{\frac{\left(m S_{T}+n B\right) \kappa}{m+n \kappa}, F+c_{M}\right\} \\
V_{k, t} & \geq \frac{\left(m S_{t}+n F\right) \kappa}{m+n \kappa}, \quad t \in\left[T_{\text {con }}, T\right] \\
V_{k, t} & \geq B_{p}, \quad t \in\left[T_{\text {put }}, T\right] \\
V_{k, t} & \leq \max \left\{\frac{\left(m S_{t}+n F\right) \kappa}{m+n \kappa}, B_{c}\right\}, \quad t \in\left[T_{\text {call }}, T\right] \\
V_{k, t c_{i}}^{+} & =V_{k, t c_{i}}^{-}-c_{i}, \quad i=1,2, \ldots, M-1 .
\end{aligned}
$$

In fact, the model (24) is a boundary value problem. We can solve this boundary value problem by using the theory of partial difference equation. But the boundary problem is difficult that it has no explicit solution. What is more, if we set $\lambda_{1}=\lambda_{2}=\cdots=\lambda_{L}=0$, the model (24) becomes the pricing model of the convertible bonds without credit risk. Hence, we can treat the pricing model without credit risk as a special case of the model (24).

\section{Dilution Effect and Debt Leverage}

As King [27] showed, dilution and leverage have effect on the value of convertible bond. Thus, the dilution effect and 
debt leverage will be considered in the pricing model in this section. The dilution effect of the convertible bonds stems from the issuance of new shares when the convertible bonds are converted. In the model (24), the dilution effect has been taken into account. Thus, we only consider the debt leverage in the following discussion. As we know, the debt leverage, or financial leverage, is often used as an indicator of financial risk. So once the debt leverage changes, the risk of shareholders' returns may be changed. Hence, the volatility of the shares returns will be affected by debt leverage. This inspires us to modify the volatility to reflect the effect of the debt leverage on the convertible bond value. Thus, the volatility in the pricing model of the convertible bonds should be the volatility after the convertible bond issues or modification of historical volatility before convertible bond issues.

MM theory about the impact of the financial leverage on the capital cost and the risk provides us with a good idea to deal with the debt leverage. For simplicity, we add some necessary assumptions based on the Black-Scholes theory as follows.

(1) No convertible bond issuance cost. The convertible bond issues at par value.

(2) There are no new bonds, the convertible bonds and the warrants issuing during the existence of the convertible bonds. The level of debt is stable during the existence of the convertible bonds.

(3) The operational efficiency risk is unchanged during the existence of the convertible bonds, and the return and risk of the capital are the same as before.

(4) The return rate and volatility of the stocks are the same as that of the ownership.

Following the assumptions and MM theory, we have the modification of the historical volatility of the stocks as Proposition 1.

Proposition 1. There are $m$ stocks and $n$ convertible bonds issued by the company right now. Let $E, D_{0}$, and $D_{1}$ be the market value of the company owner' equity, the market value of corporate liabilities, and the total face value of the convertible bonds. Let $\sigma_{k, 0}$ and $\sigma_{k, 1}(k=1,2, \ldots, L)$ be the volatility of the stocks at $k$ th regime before and after the convertible bonds issue. Let $\rho$ be income tax rate of enterprise. Then

$$
\begin{aligned}
\sigma_{k, 1} & =\frac{E+\left(D_{0}+D_{1}\right)(1-\rho)}{E+D_{0}(1-\rho)} \sigma_{k, 0} \\
& =\frac{m S_{0}+\left(D_{0}+m F\right)(1-\rho)}{m S_{0}+D_{0}(1-\rho)} \sigma_{k, 0} .
\end{aligned}
$$

Proof. Let $r_{k, 0}$ and $r_{k, 1}$ be the returns of owner's equity at the $k$ th regime. Let $r_{k, u}$ and $\sigma_{k, u}$ be the corporate returns and the volatility at the $k$ th regime without any debt. Let $r_{k, d}$ be the average rate of the corporate debt at the $k$ th regime. Because there is not any income except the convertible bonds when the convertible bonds issue, the owner's equity is unchanged. Then the relationship between the rate of shareholders returns with and without debt at the $k$ th regime satisfies

$$
\begin{aligned}
r_{k, 0} & =r_{k, u}+\frac{D_{0}}{E}\left(r_{k, u}-r_{k, d}\right)(1-\rho) \\
& =\frac{E+D_{0}(1-\rho)}{E} r_{k, u}-\frac{D_{0}(1-\rho)}{E} r_{k, d}, \quad k=1,2, \ldots, L .
\end{aligned}
$$

Because $r_{k, d}$ is constant when the debt is known, taking the variance of both sides of (26), we have

$$
\begin{aligned}
\sigma_{k, 0}^{2} & =\operatorname{Var}\left[r_{k, 0}\right]=\left(\frac{E+D_{0}(1-\rho)}{E}\right)^{2} \operatorname{Var}\left[r_{k, u}\right] \\
& =\left(\frac{E+D_{0}(1-\rho)}{E} \sigma_{k, u}\right)^{2} .
\end{aligned}
$$

Similarly, we can derive the relationship between the volatility before and after the convertible bonds issue as follows:

$$
\begin{aligned}
\sigma_{k, 1}^{2} & =\operatorname{Var}\left[r_{k, 1}\right]=\left(\frac{E+\left(D_{0}+D_{1}\right)(1-\rho)}{E} \sigma_{k, u}\right)^{2} \\
& =\left(\frac{E+\left(D_{0}+D_{1}\right)(1-\rho)}{E+D_{0}(1-\rho)} \sigma_{k, 0}\right)^{2}
\end{aligned}
$$

Comparing (27) and (28), we deduce

$$
\sigma_{k, 1}=\frac{E+D_{0}+D_{1}}{E+D_{0}} \sigma_{k, 0}=\frac{m S_{0}+\left(D_{0}+n F\right)(1-\rho)}{m S_{0}+D_{0}(1-\rho)} \sigma_{k, 0} .
$$

This completes the proof.

Following Proposition 1, we can easily get modified volatility of the model (24) when debt leverage is considered. But it is worth noting that the method is only applicable for historical volatility, not for implied volatility and other volatilities, which are the current volatilities after the convertible bonds issue so that the debt leverage is concluded and the volatilities are not necessary to be modified.

\section{Numerical Solutions}

The pricing model of the convertible bonds with credit risk under regime switching introduced in Section 2 is complex and hard to achieve an exact solution, so we need the numerical solution method to solve this model. The main numerical solution methods of convertible bonds pricing include the finite difference method, the finite element method, the binomial or the trinomial tree, and the Monte Carlo simulation. The finite difference method is a basic one that solves directly the partial difference equation with the boundary conditions. The tree model is another basic one that solves the pricing problem based on the process of stock price. What is more, without regime switching, it is known that the tree model is consistent with the finite difference method. Here we will choose the finite difference method and the tree model to solve the pricing problem. In this section we will give the details of the finite difference and the trinomial tree to solve this pricing model and explore their consistency. 
4.1. The Finite Difference Scheme. The finite difference method is the most basic numerical solution of convertible bond pricing by solving the partial difference equation. We can improve the accuracy and get satisfactory result by increasing time steps and price steps. For convergence effect and convergence rate of the finite difference method, we apply the Crank-Nicolson method to solve the model (18) and get approximate solution. Divide the area $[t, T] \times\left[0, S_{\max }\right]$ into $M \times N$ small identical rectangles. Set $\Delta t=(T-t) / M$ and $\Delta S=S_{\max } / N$. Let $V_{k, i, j}$ be the price of the convertible bond under the $k$ th regime, time $i \Delta t$, and stock price $j \Delta t$. To get the Euler explicit scheme, we write the difference approximation as

$$
\begin{gathered}
\frac{\partial V_{k}}{\partial t}=\frac{V_{k, i+1, j}-V_{k, i, j}}{\Delta t}, \quad \frac{\partial V_{k}}{\partial S}=\frac{V_{k, i, j+1}-V_{k, i, j-1}}{2 \Delta S}, \\
\frac{\partial V_{k}^{2}}{\partial^{2} S}=\frac{V_{k, i, j+1}+V_{k, i, j-1}-2 V_{k, i, j}}{\Delta S^{2}} .
\end{gathered}
$$

Substituting (30) in (18), we have

$$
\begin{aligned}
& \frac{V_{k, i+1, j}-V_{k, i, j}}{\Delta t}+\left(r_{k}-q_{k}+\lambda_{k} \eta_{k}\right) j \Delta S \frac{V_{k, i, j+1}-V_{k, i, j-1}}{2 \Delta S} \\
& +\frac{1}{2} \sigma_{k}^{2} j^{2} \Delta S^{2} \frac{V_{k, i, j+1}+V_{k, i, j-1}-2 V_{k, i, j}}{\Delta S^{2}}-\left(r_{k}+\lambda_{k}\right) V_{k, i, j} \\
& +\lambda_{k} \max \left(R_{k} B, \kappa\left(1-\eta_{k}\right) j \Delta S\right)+\sum_{l=1}^{L} a_{k l} V_{l, i, j}=0 .
\end{aligned}
$$

To get the Euler implicit scheme, we write the difference approximation as

$$
\begin{gathered}
\frac{\partial V_{k}}{\partial t}=\frac{V_{k, i+1, j}-V_{k, i, j}}{\Delta t}, \quad \frac{\partial V_{k}}{\partial S}=\frac{V_{k, i+1, j+1}-V_{k, i+1, j-1}}{2 \Delta S}, \\
\frac{\partial V_{k}^{2}}{\partial^{2} S}=\frac{V_{k, i+1, j+1}+V_{k, i+1, j-1}-2 V_{k, i+1, j}}{\Delta S^{2}}
\end{gathered}
$$

Substituting (32) in (18), we get

$$
\begin{aligned}
& \frac{V_{k, i+1, j}-V_{k, i, j}}{\Delta t}+\left(r_{k}-q_{k}+\lambda_{k} \eta_{k}\right) j \Delta S \frac{V_{k, i+1, j+1}-V_{k, i+1, j-1}}{2 \Delta S} \\
& +\frac{1}{2} \sigma_{k}^{2} j^{2} \Delta S^{2} \frac{V_{k, i+1, j+1}+V_{k, i+1, j-1}-2 V_{k, i+1, j}}{\Delta S^{2}} \\
& -\left(r_{k}+\lambda_{k}\right) V_{k, i, j}+\lambda_{k} \max \left(R_{k} B, \kappa\left(1-\eta_{k}\right) j \Delta S\right) \\
& +\sum_{l=1}^{L} a_{k l} V_{l, i, j}=0 .
\end{aligned}
$$

By (31) and (33), we obtain

$$
\begin{aligned}
& \frac{V_{k, i+1, j}-V_{k, i, j}}{\Delta t}+\left(r_{k}-q_{k}+\lambda_{k} \eta_{k}\right) \\
& \times j \frac{V_{k, i, j+1}-V_{k, i, j-1}+V_{k, i+1, j+1}-V_{k, i+1, j-1}}{4}
\end{aligned}
$$

$$
\begin{gathered}
-\left(r_{k}+\lambda_{k}\right) V_{k, i, j}+\sum_{l=1}^{L} a_{k l} V_{l, i, j} \\
+\frac{1}{4} \sigma_{k}^{2} j^{2}\left(V_{k, i+1, j+1}+V_{k, i+1, j-1}-2 V_{k, i+1, j}\right. \\
\left.+V_{k, i, j+1}+V_{k, i, j-1}-2 V_{k, i, j}\right) \\
+\lambda_{k} \max \left(R_{k} B, \kappa\left(1-\eta_{k}\right) j \Delta S\right)=0 .
\end{gathered}
$$

Multiplying $\Delta t$ at both sides of (34), transposing, and simplifying, we get

$$
\begin{aligned}
& {\left[\frac{1}{4}\left(r_{k}-q_{k}+\lambda_{k} \eta_{k}\right) j \Delta t-\frac{1}{4} \sigma_{k}^{2} j^{2} \Delta t\right] V_{k, i, j-1} } \\
&+ {\left[1+\frac{1}{4}\left(r_{k}+\lambda_{k}\right) j \Delta t+\frac{1}{2} \sigma_{k}^{2} j^{2} \Delta t\right] V_{k, i, j} } \\
&+ {\left[-\frac{1}{4}\left(r_{k}-q_{k}+\lambda_{k} \eta_{k}\right) j \Delta t-\frac{1}{4} \sigma_{k}^{2} j^{2} \Delta t\right] V_{k, i, j+1} } \\
&-\sum_{l=1}^{L} a_{k l} V_{l, i, j} \\
&=-\frac{1}{4}\left(r_{k}-q_{k}+\lambda_{k} \eta_{k}\right) j \Delta t \\
&\left.+\frac{1}{4} \sigma_{k}^{2} j^{2} \Delta t\right] V_{k, i+1, j-1} \\
&+ {\left[1-\frac{1}{2} \sigma_{k}^{2} j^{2} \Delta t\right] V_{k, i+1, j} } \\
&+ {\left[\frac{1}{4}\left(r_{k}-q_{k}+\lambda_{k} \eta_{k}\right) j \Delta t+\frac{1}{4} \sigma_{k}^{2} j^{2} \Delta t\right] V_{k, i+1, j+1} } \\
&+ \lambda_{k} \Delta t \max \left(R_{k} B, \kappa\left(1-\eta_{k}\right) j \Delta S\right) .
\end{aligned}
$$

Solving (35) from time $(N-1) \Delta t$ to time 0 recursively and taking into account the constraints of the convertible bonds, we can achieve the price of the convertible bonds at any time and any stock price. Furthermore, there are always an upper bound and a lower bound in the finite difference model. Here we set

$$
\begin{aligned}
& V_{k, i, N+1}=\kappa N \Delta S, \quad V_{k, i, 1}=0, \\
& k=1,2, \ldots, L, i=1,2, \ldots, M
\end{aligned}
$$

Early studies have shown that the Crank-Nicolson scheme is second-order convergence which refers to time. Therefore, the convertible bond price calculated by the finite difference converges to the theoretical value when the interval $\Delta t$ tends to infinity small.

4.2. The Trinomial Tree Model. The trinomial tree model is another important numerical solution and is widely used in derivatives pricing. The trinomial tree method has advantage in computational efficiency to the finite difference method. In the following section we are going to apply the trinomial tree to the valuation of convertible bonds. We divide interval $[t, T]$ 
into $M$ small identical intervals and set $\Delta t=(T-t) / M$. When the market state is in the $k$ th regime, the default probability is

$$
w_{k}=1-e^{-\lambda_{k} \Delta t}=\lambda_{k} \Delta t+o(\Delta t) \approx \lambda_{k} \Delta t, \quad k=1,2, \ldots, L .
$$

Following the trinomial tree of Boyle [28], we set

$$
\begin{aligned}
& u_{k}=e^{\alpha_{k} \sigma_{k} \sqrt{\Delta t}}, \quad d_{k}=\frac{1}{u_{k}}=e^{-\alpha_{k} \sigma_{k} \sqrt{\Delta t}}, \\
& m_{k}=1, \quad \alpha_{k}>0, \quad k=1,2, \ldots, L .
\end{aligned}
$$

Let $\pi_{k, u}, \pi_{k, m}, \pi_{k, d}(k=1,2, \ldots, L)$ denote the probability when the stock price increases, remains, and decreases, respectively. Considering the expected return and volatility of stock price under the risk-neutral market and applying the risk-free arbitrage principle, these jump probabilities satisfy

$$
\begin{aligned}
& \pi_{k, u}+\pi_{k, m}+\pi_{k, d}=1, \\
& \pi_{k, u} u_{k}+\pi_{k, m}+\pi_{k, d} d_{k}=e^{\left(r_{k}+\lambda_{k} \eta_{k}-q_{k}\right) \Delta t}, \\
& \pi_{k, u} u_{k}^{2}+\pi_{k, m}+\pi_{k, d} d_{k}^{2}=e^{2\left(r_{k}+\lambda_{k} \eta_{k}-q_{k}\right) \Delta t+\sigma_{k}^{2} \Delta t}, \quad k=1,2, \ldots, L .
\end{aligned}
$$

Solving (39), we have

$$
\begin{aligned}
& \pi_{k, u}=\frac{\left(U_{k}-Q_{k}\right)-u_{k}\left(Q_{k}-1\right)}{\left(u_{k}-d_{k}\right)\left(1-d_{k}\right)}, \\
& \pi_{k, d}=\frac{\left(U_{k}-Q_{k}\right)-d_{k}\left(Q_{k}-1\right)}{\left(u_{k}-d_{k}\right)\left(u_{k}-1\right)}, \\
& \pi_{k, m}=1-\pi_{k, u}-\pi_{k, d}, \quad k=1,2, \ldots, L,
\end{aligned}
$$

where $U_{k}=e^{\left(r_{k}+\lambda_{k} \eta_{k}-q_{k}\right) \Delta t}, Q_{k}=e^{2\left(r_{k}+\lambda_{k} \eta_{k}-q_{k}\right) \Delta t+\sigma_{k}^{2}}$. Then, we get the recurrence relation equations as

$$
\begin{gathered}
V(k, S, t) \\
=\sum_{l=1}^{L} p_{k l} e^{-r_{l} \Delta t}\left\{\pi _ { l , u } \left[\left(1-w_{l}\right) V\left(l, u_{l} S, t+\Delta t\right)\right.\right. \\
\left.+w_{l} \max \left(R_{l} B, \kappa\left(1-\eta_{l}\right) u_{l} S\right)\right] \\
+\pi_{l, u}\left[\left(1-w_{l}\right) V\left(l, m_{l} S, t+\Delta t\right)\right. \\
\left.+w_{l} \max \left(R_{l} B, \kappa\left(1-\eta_{l}\right) m_{l} S\right)\right] \\
+\pi_{l, u}\left[\left(1-w_{l}\right) V\left(l, d_{l} S, t+\Delta t\right)\right. \\
\left.\left.+w_{l} \max \left(R_{l} B, \kappa\left(1-\eta_{l}\right) d_{l} S\right)\right]\right\} \\
=\sum_{l=1}^{L} p_{k l} e^{-r_{l} \Delta t}\left\{( 1 - w _ { l } ) \left[\pi_{l, u} V\left(l, u_{l} S, t+\Delta t\right)\right.\right. \\
+\pi_{l, m} V\left(l, m_{l} S, t+\Delta t\right) \\
\left.+\pi_{l, d} V\left(l, d_{l} S, t+\Delta t\right)\right]
\end{gathered}
$$

$$
\begin{aligned}
+w_{l}[ & \pi_{l, u} \max \left(R_{l} B, \kappa\left(1-\eta_{l}\right) u_{l} S\right) \\
& +\pi_{l, m} \max \left(R_{l} B, \kappa\left(1-\eta_{l}\right) m_{l} S\right) \\
& \left.\left.+\pi_{l, d} \max \left(R_{l} B, \kappa\left(1-\eta_{l}\right) d_{l} S\right)\right]\right\} .
\end{aligned}
$$

We can set the parameter $\alpha_{k}$ to decrease nodes of the trinomial tree. Thus, we set

$$
\alpha_{k}=\frac{\sigma_{0}}{\sigma_{k}}, \quad k=1,2, \ldots, L, \sigma_{0}>\max _{1 \leq k \leq L}\left(\sigma_{k}\right) .
$$

That is,

$$
\begin{array}{r}
u_{k}=e^{\sigma_{0} \sqrt{\Delta t}}, \quad d_{k}=e^{-\sigma_{0} \sqrt{\Delta t}}, \quad m_{k}=1, \\
k=1,2, \ldots, L .
\end{array}
$$

Yuen and Yang [23] proposed that $\sigma_{0}$ should be taken as

$$
\sigma_{0}=\max _{1 \leq k \leq L}\left(\sigma_{k}\right)+(\sqrt{1.5}-1) \operatorname{mean}_{1 \leq k \leq L}\left(\sigma_{k}\right)
$$

Thus, the number of the nodes of the trinomial tree decreases so much that we can save many storage spaces and much computation time.

4.3. The Consistency of the Finite Difference and the Trinomial Tree. As we know, without regime switching, the tree model is consistent with the finite difference method, so we are going to explore their consistency with regime switching. Starting with the trinomial tree, we can achieve the relation between the trinomial tree model and the partial differential equations as the following proposition.

Proposition 2. When the interval $\Delta t$ tends to zero, (41) converges to (18).

Proof. For any $b>0$, applying the multivariate Taylor's series, we have

$$
\begin{aligned}
V(k, b S, t) \\
=V(k, S+(b-1) S, t+\Delta t) \\
=V(k, S, t)+(b-1) S \frac{\partial V}{\partial S}+\Delta t \frac{\partial V}{\partial t} \\
\quad+\frac{1}{2}(b-1)^{2} S^{2} \frac{\partial V}{\partial S}+o(\Delta t) .
\end{aligned}
$$

Then, we obtain

$$
\begin{aligned}
\pi_{k, u} V & \left(k, u_{k} S, t+\Delta t\right)+\pi_{k, m} V\left(k, m_{k} S, t+\Delta t\right) \\
+ & \pi_{k, d} V\left(k, d_{k} S, t+\Delta t\right) \\
= & \left(\pi_{k, u}+\pi_{k, m}+\pi_{k, d}\right)\left(V(k, S, t)+\Delta t \frac{\partial V}{\partial t}\right) \\
+ & \left(\left(\pi_{k, u} u_{k}+\pi_{k, m} m_{k}+\pi_{k, d} d_{k}\right)\right. \\
& \left.-\left(\pi_{k, u}+\pi_{k, m}+\pi_{k, d}\right)\right) S \frac{\partial V}{\partial S} \\
+ & \frac{1}{2}\left(\left(\pi_{k, u} u_{k}^{2}+\pi_{k, m} m_{k}^{2}+\pi_{k, d} d_{k}^{2}\right)\right.
\end{aligned}
$$




$$
\begin{gathered}
-2\left(\pi_{k, u} u_{k}+\pi_{k, m} m_{k}+\pi_{k, d} d_{k}\right) \\
\left.+\left(\pi_{k, u}+\pi_{k, m}+\pi_{k, d}\right)\right) S^{2} \frac{\partial V}{\partial S}+o(\Delta t) \\
=V(k, S, t)+\Delta t \frac{\partial V}{\partial t}+\left(e^{\left(r_{k}+\lambda_{k} \eta_{k}\right) \Delta t}-1\right) S \frac{\partial V}{\partial S} \\
+\frac{1}{2}\left(e^{2\left(r_{k}+\lambda_{k} \eta_{k}\right) \Delta t+\sigma_{k}^{2} \Delta t}-2 e^{\left(r_{k}+\lambda_{k} \eta_{k}\right) \Delta t}+1\right) \\
\times S^{2} \frac{\partial V}{\partial S}+o(\Delta t) \\
=V(k, S, t)+\Delta t \frac{\partial V}{\partial t}+\left(r_{k}+\lambda_{k} \eta_{k}\right) S \Delta t \frac{\partial V}{\partial S} \\
+\frac{1}{2} \sigma_{k}^{2} S^{2} \Delta t \frac{\partial V}{\partial S}+o(\Delta t) .
\end{gathered}
$$

Multiplying $\prod_{h=1}^{L} e^{r_{l} \Delta t}$ both sides of (41), we have

$$
\begin{gathered}
\left(\prod_{h=1}^{L} e^{r_{l} \Delta t}\right) V(k, S, t) \\
=\sum_{l=1}^{L} p_{k l}\left(\prod_{h \neq l} e^{r_{h} \Delta t}\right) \\
\times\left\{( 1 - w _ { l } ) \left[\pi_{l, u} V\left(l, u_{l} S, t+\Delta t\right)\right.\right. \\
+\pi_{l, m} V\left(l, m_{l} S, t+\Delta t\right) \\
\left.+\pi_{l, d} V\left(l, d_{l} S, t+\Delta t\right)\right] \\
+w_{l}\left[\pi_{l, u} \max \left(R_{l} B, \kappa\left(1-\eta_{l}\right) u_{l} S\right)\right. \\
+\pi_{l, m} \max \left(R_{l} B, \kappa\left(1-\eta_{l}\right) m_{l} S\right) \\
\left.\left.+\pi_{l, d} \max \left(R_{l} B, \kappa\left(1-\eta_{l}\right) d_{l} S\right)\right]\right\} .
\end{gathered}
$$

Applying Taylor's series, we have

$$
\begin{aligned}
& \left(\prod_{h=1}^{L}\left(1+r_{h} \Delta t+o(\Delta t)\right)\right) V(k, S, t) \\
& =\left(1+\sum_{h=1}^{L} r_{h} \Delta t+o(\Delta t)\right) V(k, S, t) \\
& =\left(1+a_{k k} \Delta t+o(\Delta t)\right)\left(\prod_{h \neq k}\left(1+r_{h} \Delta t+o(\Delta t)\right)\right) \\
& \times\left\{\left(1-\lambda_{k} \Delta t+o(\Delta t)\right)\right. \\
& \times\left[V(k, S, t)+\Delta t \frac{\partial V}{\partial t}+\left(r_{k}+\lambda_{k} \eta_{k}\right) S \Delta t \frac{\partial V}{\partial S}\right. \\
& \left.+\frac{1}{2} \sigma_{k}^{2} S^{2} \Delta t \frac{\partial V}{\partial S}+o(\Delta t)\right]
\end{aligned}
$$

$$
\begin{aligned}
& +\left(\lambda_{k} \Delta t+o(\Delta t)\right) \\
& \times\left[\pi_{k, u} \max \left(R_{k} B, \kappa\left(1-\eta_{k}\right) u_{k} S\right)\right. \\
& +\pi_{k, m} \max \left(R_{k} B, \kappa\left(1-\eta_{k}\right) m_{k} S\right) \\
& \left.\left.+\pi_{k, d} \max \left(R_{k} B, \kappa\left(1-\eta_{k}\right) d_{k} S\right)\right]\right\} \\
& +\sum_{l \neq k}\left(a_{k l} \Delta t+o(\Delta t)\right)\left(\prod_{h \neq l}\left(1+r_{h} \Delta t+o(\Delta t)\right)\right) \\
& \times\left\{\left(1-\lambda_{l} \Delta t+o(\Delta t)\right)\right. \\
& \times\left[V(l, S, t)+\Delta t \frac{\partial V}{\partial t}+\left(r_{l}+\lambda_{l} \eta_{l}\right) S \Delta t \frac{\partial V}{\partial S}\right. \\
& \left.+\frac{1}{2} \sigma_{l}^{2} S^{2} \Delta t \frac{\partial V}{\partial S}+o(\Delta t)\right] \\
& +\left(\lambda_{l} \Delta t+o(\Delta t)\right) \\
& \times\left[\pi_{l, u} \max \left(R_{l} B, \kappa\left(1-\eta_{l}\right) u_{l} S\right)\right. \\
& +\pi_{l, m} \max \left(R_{l} B, \kappa\left(1-\eta_{l}\right) m_{l} S\right) \\
& \left.\left.+\pi_{l, d} \max \left(R_{l} B, \kappa\left(1-\eta_{l}\right) d_{l} S\right)\right]\right\} \\
& =\left(1+a_{k k} \Delta t+o(\Delta t)\right)\left(1+\sum_{h \neq k} r_{h} \Delta t+o(\Delta t)\right) \\
& \times\left\{\left(1-\lambda_{k} \Delta t+o(\Delta t)\right)\right. \\
& \times\left[V(k, S, t)+\Delta t \frac{\partial V}{\partial t}+\left(r_{k}+\lambda_{k} \eta_{k}\right) S \Delta t \frac{\partial V}{\partial S}\right. \\
& \left.+\frac{1}{2} \sigma_{k}^{2} S^{2} \Delta t \frac{\partial V}{\partial S}+o(\Delta t)\right] \\
& +\left(\lambda_{k} \Delta t+o(\Delta t)\right) \\
& \times\left[\pi_{k, u} \max \left(R_{k} B, \kappa\left(1-\eta_{k}\right) u_{k} S\right)\right. \\
& +\pi_{k, m} \max \left(R_{k} B, \kappa\left(1-\eta_{k}\right) m_{k} S\right) \\
& \left.\left.+\pi_{k, d} \max \left(R_{k} B, \kappa\left(1-\eta_{k}\right) d_{k} S\right)\right]\right\} \\
& +\sum_{l \neq k}\left(a_{k l} \Delta t+o(\Delta t)\right)\left(1+\sum_{h \neq l} r_{h} \Delta t+o(\Delta t)\right) \\
& \times\left\{\left(1-\lambda_{l} \Delta t+o(\Delta t)\right)\right. \\
& \times\left[V(l, S, t)+\Delta t \frac{\partial V}{\partial t}+\left(r_{l}+\lambda_{l} \eta_{l}\right) S \Delta t \frac{\partial V}{\partial S}\right. \\
& \left.+\frac{1}{2} \sigma_{l}^{2} S^{2} \Delta t \frac{\partial V}{\partial S}+o(\Delta t)\right]
\end{aligned}
$$




$$
\begin{gathered}
+\left(\lambda_{l} \Delta t+o(\Delta t)\right) \\
\times\left[\pi_{l, u} \max \left(R_{l} B, \kappa\left(1-\eta_{l}\right) u_{l} S\right)\right. \\
+\pi_{l, m} \max \left(R_{l} B, \kappa\left(1-\eta_{l}\right) m_{l} S\right) \\
\left.\left.+\pi_{l, d} \max \left(R_{l} B, \kappa\left(1-\eta_{l}\right) d_{l} S\right)\right]\right\} \\
=V(k, S, t)+\Delta t \frac{\partial V}{\partial t}+\left(r_{k}+\lambda_{k} \eta_{k}\right) S \Delta t \frac{\partial V}{\partial S} \\
+\frac{1}{2} \sigma_{k}^{2} S^{2} \Delta t \frac{\partial V}{\partial S}-\lambda_{k} V_{k} \Delta t+\sum_{h \neq k} r_{h} V_{k} \Delta t \\
+\sum_{l=1}^{L} a_{k l} V_{k} \Delta t+o(\Delta t) \\
+\lambda_{k} \Delta t\left[\pi_{k, u} \max \left(R_{k} B, \kappa\left(1-\eta_{k}\right) u_{k} S\right)\right. \\
+\pi_{k, m} \max \left(R_{k} B, \kappa\left(1-\eta_{k}\right) m_{k} S\right) \\
\left.+\pi_{k, d} \max \left(R_{k} B, \kappa\left(1-\eta_{k}\right) d_{k} S\right)\right] .
\end{gathered}
$$

Eliminating the similar items of (48), we have

$$
\begin{array}{r}
r_{k} V_{k} \Delta t \\
=\Delta t \frac{\partial V}{\partial t}+\left(r_{k}+\lambda_{k} \eta_{k}\right) S \Delta t \frac{\partial V}{\partial S}+\frac{1}{2} \sigma_{k}^{2} S^{2} \Delta t \frac{\partial V}{\partial S} \\
-\lambda_{k} V_{k} \Delta t+\sum_{l=1}^{L} a_{k l} V_{k} \Delta t+o(\Delta t) \\
+\lambda_{k} \Delta t\left[\pi_{k, u} \max \left(R_{k} B, \kappa\left(1-\eta_{k}\right) u_{k} S\right)\right. \\
+\pi_{k, m} \max \left(R_{k} B, \kappa\left(1-\eta_{k}\right) m_{k} S\right) \\
\left.+\pi_{k, d} \max \left(R_{k} B, \kappa\left(1-\eta_{k}\right) d_{k} S\right)\right] .
\end{array}
$$

Let both sides of (49) be divided by $\Delta t$. Then, we have

$$
\begin{array}{r}
\lambda_{k} V_{k} \\
=\frac{\partial V}{\partial t}+\left(r_{k}+\lambda_{k} \eta_{k}\right) S \frac{\partial V}{\partial S}+\frac{1}{2} \sigma_{k}^{2} S^{2} \frac{\partial V}{\partial S} \\
\quad-\lambda_{k} V_{k}+\sum_{l=1}^{L} a_{k l} V_{k}+o(1) \\
+\lambda_{k}\left[\pi_{k, u} \max \left(R_{k} B, \kappa\left(1-\eta_{k}\right) u_{k} S\right)\right. \\
\quad+\pi_{k, m} \max \left(R_{k} B, \kappa\left(1-\eta_{k}\right) m_{k} S\right) \\
\left.\quad+\pi_{k, d} \max \left(R_{k} B, \kappa\left(1-\eta_{k}\right) d_{k} S\right)\right] .
\end{array}
$$

Let $\Delta t \rightarrow 0$; (50) converges to

$$
\begin{gathered}
\frac{\partial V}{\partial t}+\left(r_{k}+\lambda_{k} \eta_{k}\right) S \frac{\partial V}{\partial S}+\frac{1}{2} \sigma_{k}^{2} S^{2} \frac{\partial V}{\partial S} \\
-\left(r_{k}+\lambda_{k}\right) V_{k}+\sum_{l=1}^{L} a_{k l} V_{k} \\
+\lambda_{k} \max \left(R_{k} B, \kappa\left(1-\eta_{k}\right) S\right)=0 .
\end{gathered}
$$

This completes the proof.

Proposition 2 indicates that the trinomial tree model of the convertible bonds with credit risk under regime switching is consistent with the partial differential equations of the convertible bonds. That is, the trinomial tree model of the convertible bonds is consistent with the finite difference model of the convertible bonds.

\section{Numerical Example and Analysis}

In order to explore the effect of credit risk and regime switching on the value of the convertible bonds and show the difference of the pricing efficiency between the trinomial tree method and the finite difference method, we will introduce a numerical example in this section. The information of the convertible bonds used for the numerical example is given in Table 1.

First of all, we will compare the convergence, pricing effectiveness, and efficiency of the numerical solutions for the trinomial tree method and the finite difference method. For simplifying, we assume that there are only two states in the market. The parameters of the stock price process and the default used for the numerical example are given in Table 2.

We assume that the current stock price is 10 , the corporate income tax rate is $25 \%$, and there is no call provision. Let the generator matrix be

$$
A=\left(\begin{array}{cc}
-0.5 & 0.5 \\
0.5 & -0.5
\end{array}\right)
$$

For the finite difference method, we set that the upper bound of the stock price is equal to 30 and the number of the stock price steps is equal to 300 . For the trinomial tree, we set the parameters the same as Yuen and Yang [23]. Table 3 and Figure 1 present the numerical results for the current price and computation time of the convertible bonds for different time steps and different numerical solutions by MATLAB 7.0.

From Table 3 and Figure 1, the finite difference method is monotonically converging to the theoretical value; the trinomial tree method is also convergent but not monotonous. Although the numerical results of the trinomial tree and the finite difference are different, the difference between two numerical solutions is so small that two numerical solutions are consistent, which is the same as conclusions in Section 4.3. In terms of convergence, we need more time steps to make the numerical solution converge. However, the results tend to be stable when the number of time steps tends to infinity and the value changes a little when the number of time steps is over 2000. Hence, the numerical results are 


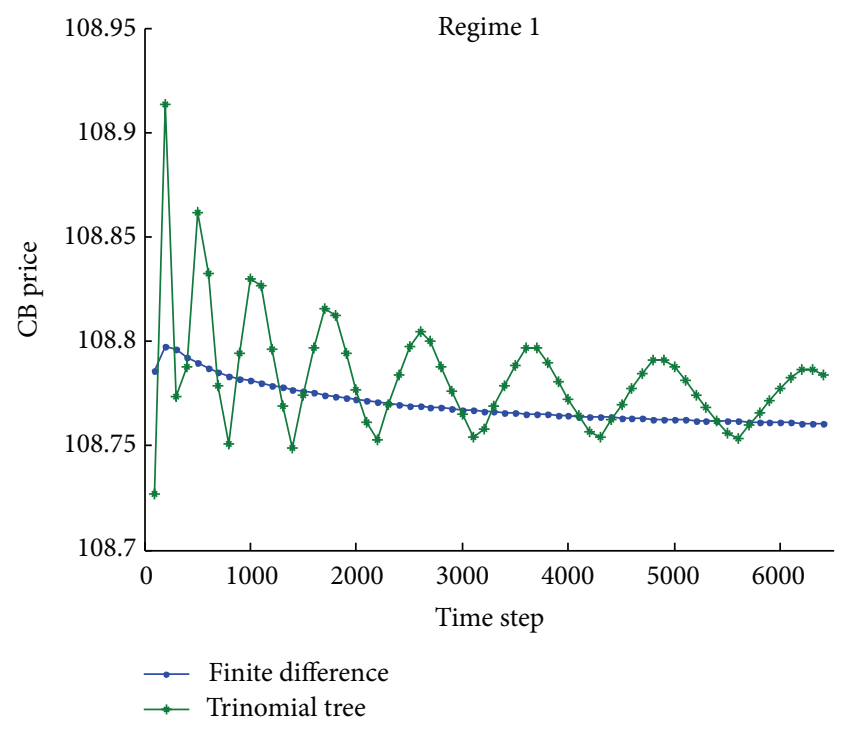

(a)

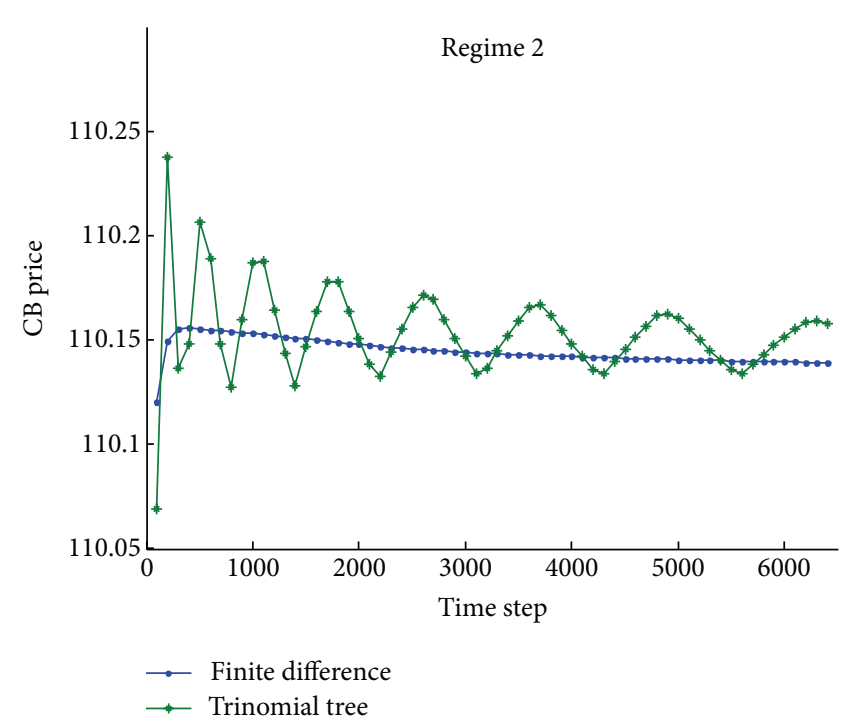

(b)

Figure 1: Comparison of the finite difference and the trinomial tree on convergence.

TABLE 1: Data for numerical example.

\begin{tabular}{lc}
\hline Face value & 100 \\
Coupon payments & $2 \%$ annually \\
Conversion ratio & 10 \\
Maturity & 5 years \\
Conversion period & $1-5$ years \\
Put period & $2-5$ years \\
Put price & 103 \\
Call period & $2-5$ years \\
Call Price & 110 \\
Amount of share & 100 million \\
Amount of convertible bonds & 1 million \\
Debt before convertible bonds & 400 million \\
\hline
\end{tabular}

acceptable when the number of time steps is over 2000. In terms of the computation time, the trinomial tree needs less time than the finite difference when the number of time steps is the same and not large. However, the trinomial tree may need more time than the finite difference when the number of time steps is large enough. What is more, the numerical result of the finite difference is more stable than that of the trinomial tree. But we should also notice that the finite difference method also achieves the convertible bond price at any time and any stock price. So it is convenient to use the finite difference to study the effect of time and stock price on the convertible bond and calculate the optimal conversion price. We can choose one numerical method as we need.

Next, we will study the relation of stock, time, and convertible bond price. Following Table 1, Table 2, and generator matrix (50), the numerical result of convertible bond pricing at different stock prices and time by the finite difference method is graphed as Figure 2.
Figure 2 shows that the trends of different regimes are the same but only different in value. Once time is given, the convertible bond price increases with the stock price increasing for the conversion value of the convertible bond. That is, the higher the stock price is, the higher the convertible bond price is. Similarly, once the stock price is given, the convertibles bond price changes wavily with the time increasing, which mainly is due to the discrete coupons payment. That is, between two coupon payments, the convertible bond price increases with the time. The reason is that the present value of the coupon increases when the time of coupon payment is near. And when the coupon is paid, the value of a convertible bond will jump with the same amount of coupon. But the height of the waves decreases with time. These indicate that the nearer the time is, the lower the convertible bond price is, which is the same as that without regime switching. The reason is that the value of option part becomes smaller and more coupons are paid when the maturity is coming.

At last, we will study the effect of regime switching on the convertible bond price. Applying the trinomial tree method, Table 1, and Table 2, let the number of time steps be 1000 . We assume that there are only two states in the market. Set

$$
A=\left(\begin{array}{cc}
-a_{1} & a_{1} \\
a_{2} & -a_{2}
\end{array}\right) .
$$

By changing the parameters $a_{1}$ and $a_{2}$ from 0 to 10 continuously, we obtain the convertible bond prices at different generator matrixes and graph the results as Figure 3.

Figure 3 shows that different generator matrixes correspond to different convertible bond prices, though another condition is the same. The larger the parameters $a_{1}$ and $a_{2}$ are, the stronger the regime switching is. The regime switching strength presents the probability and frequency of state transition. So the stronger the regime switching is, the closer the convertible bond prices at different states are. In 


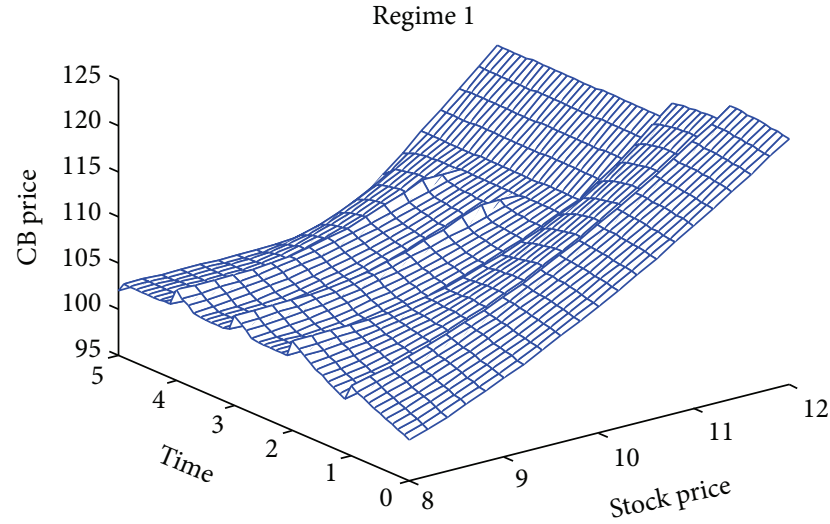

(a)

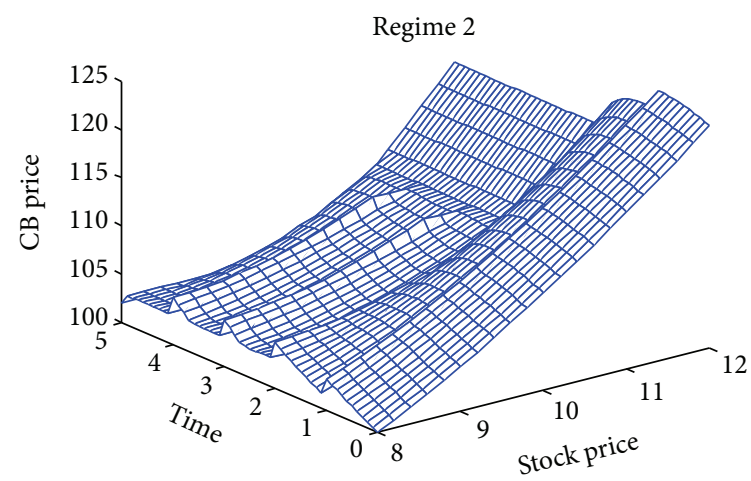

(b)

FIGURE 2: Convertible bonds value for different times and stock prices.

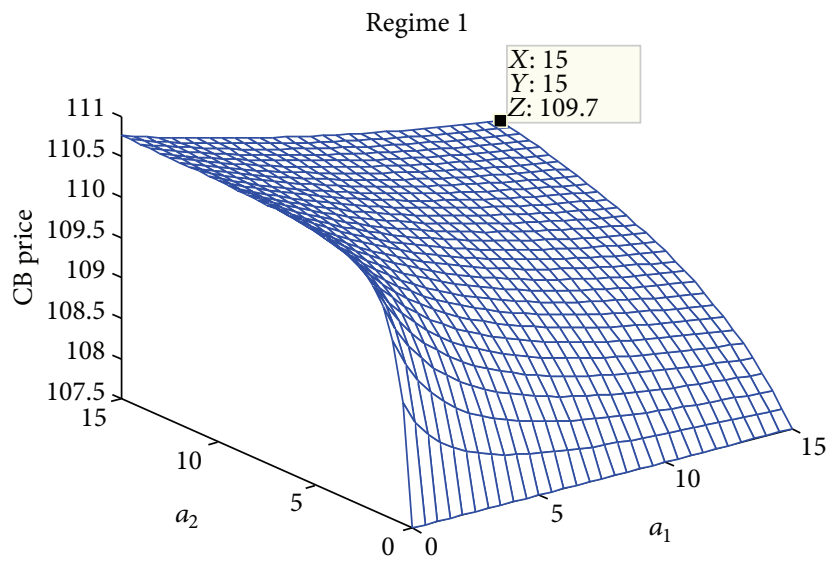

(a)

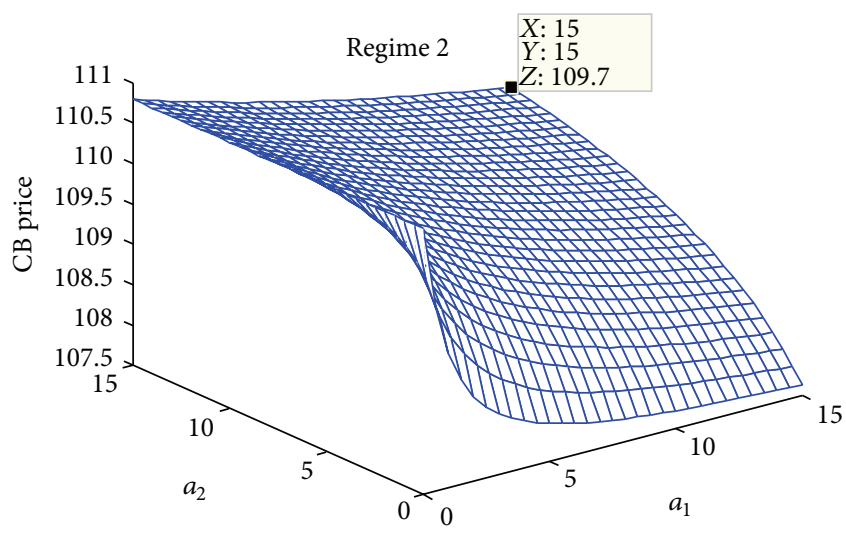

(b)

FIgURE 3: Convertible bonds value for different generator matrix.

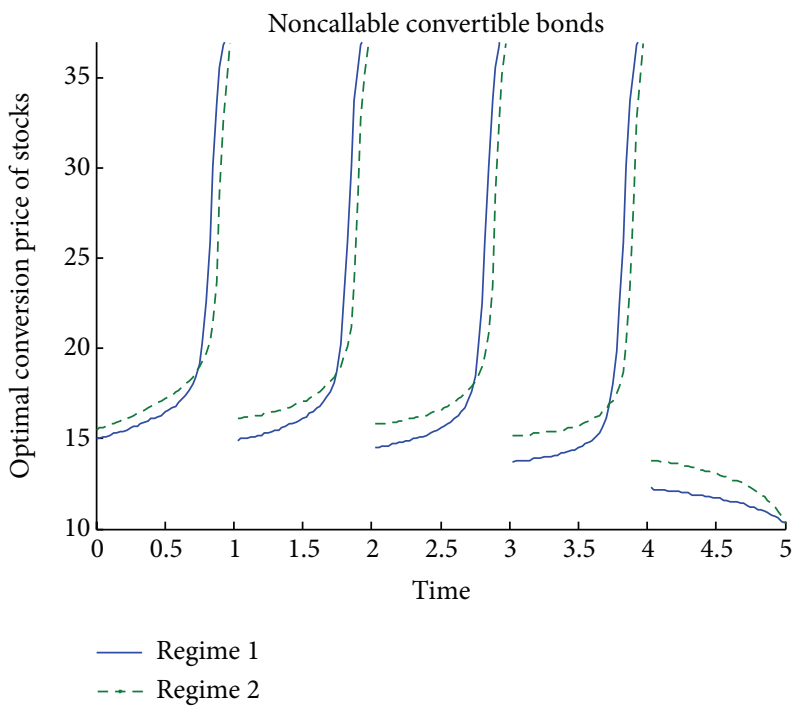

(a)

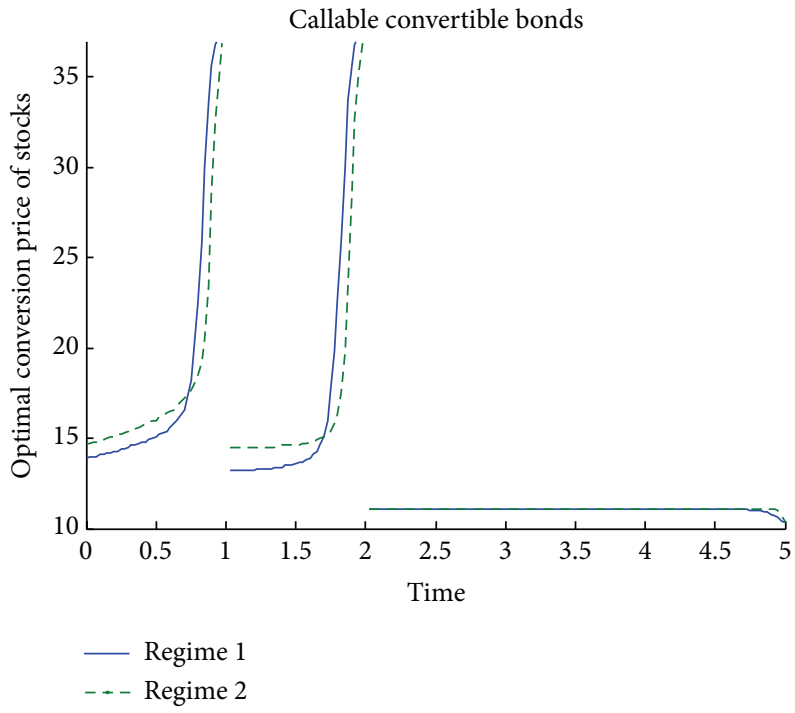

(b)

Figure 4: The optimal conversion prices of shares for callable and noncallable convertible bonds. 
TABle 2: Parameters of numerical example.

\begin{tabular}{lcccccc}
\hline Regime & Risk-free rate & Historical volatility & Continuous dividends & Hazard rate & Recovery factor & Jump ratio \\
\hline Regime 1 & 0.06 & 0.20 & 0.02 & 0.01 & 0.75 & 0.50 \\
Regime 2 & 0.08 & 0.35 & 0.03 & 0.03 & 0.50 & 0.75 \\
\hline
\end{tabular}

TABLE 3: Comparison of the finite difference and the trinomial tree.

\begin{tabular}{ccccccccc}
\hline \multicolumn{2}{c}{ Time steps } & 200 & 400 & 800 & 1600 & 3200 & 6400 & 128000 \\
\hline \multirow{2}{*}{ Finite difference } & Regime 1 & 108.7974 & 108.7925 & 108.7835 & 108.7754 & 108.7666 & 108.7606 & 108.7569 \\
& Regime 2 & 110.1492 & 110.1557 & 110.1538 & 110.1500 & 110.1437 & 110.1392 & 110.1363 \\
\multicolumn{2}{c}{ Computation time (s) } & 119.0600 & 253.1584 & 504.5852 & 1113.8 & 2275.4 & 4983.7 & 10823 \\
\hline \multirow{2}{*}{ Trinomial tree } & Regime 1 & 108.9136 & 108.7876 & 108.7509 & 1087970 & 108.7581 & 108.7841 & 108.7598 \\
& Regime 2 & 110.2378 & 110.1481 & 110.1272 & 110.1639 & 110.1367 & 110.1578 & 110.1389 \\
\multicolumn{2}{c}{ Computation time (s) } & 0.8580 & 3.1980 & 11.4817 & 46.3323 & 192.5520 & 763.3285 & 2932.1 \\
\hline
\end{tabular}

fact, when the parameters $a_{1}$ and $a_{2}$ tend to infinity together, the convertible bond prices tend to be consistent. We also find that the strength of the effect of regime switching depends on the generator matrix or the regime switching strength. Based on the theory of Markov chain, the larger the element of the generator matrix is, the more frequent one regime changes to the other. With the effect of other regimes, the value of the convertible bonds will be affected by that of other regimes. It is easy to know from this that the bigger the element of generator matrix is, the closer the value of the two regimes is. For example, the bigger $a_{1}$ is, the closer the value of regime 2 is to that of regime 1 . Here we assume there are only two states in the market, but these conclusions are also applicable for more than two states.

In addition, we can use the finite difference scheme to calculate the optimal conversion price of the convertible bond at any time. If the stock price is more than the optimal conversion price, the value of the convertible bonds is not more than their conversion value, so that the investors will always choose to convert the convertible bonds. We can calculate the optimal conversion price by seeking the least stock price in which the value of the convertible bonds is equal to their conversion price. We take the numerical example with Table 1, Table 2, and (50). The optimal conversion prices of callable and noncallable convertible bonds are presented in Figure 4.

Figure 4 indicates that the optimal conversion prices of shares at different regimes are always different except on expiry date or callable date. The reason is that the convertible bond prices at different regimes with the same conditions are always different except on expiry date or during call period, but the conversion values of convertible bonds are always the same. The regime switching has effect not only on the value of convertible bonds but also on the conversion behavior. Compared with the callable convertible bonds, the optimal conversion value of shares for noncallable convertible bonds is much lower. Within the call period, the optimal conversion price of shares is equal to the call price. If the convertible bond has a call clause, the investors may choose to convert the convertible bonds early. The unlimited call clause generally limits the value of the convertible bonds and the optimal conversion price of shares, so the issuers will set up the call clause and the put clause with some requirements or even cancel them.

\section{Conclusions}

The financial market exhibits different states in different stages, and different states interchange, such as the interconversion of "bull market" and "bear market" in the stock market. This paper has discussed the convertible bond pricing with credit risk under regime switching. We have obtained the pricing model of the convertible bonds by deriving the Black-Scholes-type partial differential equation of the convertible bonds. Considering the dilution effect and the debt leverage, we have given an operational modification on the pricing model, which offers a new idea in the convertible bond pricing. Our proposed two numerical solutions are convergent and consistent. The regime switching has effect on the value of the convertible bond; its strength depends on the generator matrix. Using this model, we can also find the optimal conversion strategy.

The proposed pricing model is one-factor model. Multifactor models including two-factor model can be studied in the future. In addition, there exists not only regime switching in the market but also other market features, such as long memory, jump, and fuzziness. Usually, these market features are mixed, not separated. Pricing convertible bonds under mixed environments will be an interesting topic in the future.

\section{Conflict of Interests}

The authors declare that there is no conflict of interests regarding the publication of this paper.

\section{Acknowledgments}

The authors would like to thank Yue Zhang for her contribution in the revision process. This research is supported by Major Project of the National Social Science Foundation of China (no. 11\&ZD156). 


\section{References}

[1] J. E. Ingersoll Jr., "A contingent-claims valuation of convertible securities," Journal of Financial Economics, vol. 4, no. 3, pp. 289321, 1977.

[2] M. J. Brennan and E. S. Schwartz, "Convertible bonds: valuation and optimal strategies for call and conversion," Journal of Finance, vol. 32, no. 5, pp. 1699-1715, 1977.

[3] J. J. McConnell and E. S. Schwartz, "LYON taming," Journal of Finance, vol. 41, no. 3, pp. 561-576, 1986.

[4] T. Kimura and T. Shinohara, "Monte Carlo analysis of convertible bonds with reset clauses," European Journal of Operational Research, vol. 168, no. 2, pp. 301-310, 2006.

[5] J. Yang, Y. Choi, S. Li, and J. Yu, "A note on 'Monte Carlo analysis of convertible bonds with reset clause," European Journal of Operational Research, vol. 200, no. 3, pp. 924-925, 2010.

[6] M. J. Brennan and E. S. Schwartz, "Analyzing convertible bonds," Journal of Financial and Quantitative Analysis, vol. 15, no. 4, pp. 907-929, 1980.

[7] M. Davis and F. Lischka, "Convertible bonds with market risk and credit default," Working Paper, Tokyo-Mitsubishi International plc., 1999.

[8] G. Barone-Adesi, A. Bermudez, and J. Hatgioannides, "Twofactor convertible bonds valuation using the method of characteristics/finite elements," Journal of Economic Dynamics and Control, vol. 27, no. 10, pp. 1801-1831, 2003.

[9] R. Xu, "A lattice approach for pricing convertible bond asset swaps with market risk and counterparty risk," Economic Modelling, vol. 28, no. 5, pp. 2143-2153, 2011.

[10] K. Yagi and K. Sawaki, "The valuation of callable-puttable reverse convertible bonds," Asia-Pacific Journal of Operational Research, vol. 27, no. 2, pp. 189-209, 2010.

[11] C. C. A. Labuschagne and T. M. Offwood, "Pricing convertible bonds using the CGMY model," Advances in Intelligent and Soft Computing, vol. 100, pp. 231-238, 2011.

[12] W. S. Lee and Y. T. Yang, "Valuation and choice of convertible bonds based on MCDM," Applied Financial Economics, vol. 23, no. 10, pp. 861-868, 2013.

[13] K. Tsiveriotis and C. Fernandes, "Valuing convertible bonds with credit risk," Journal of Fixed Income, vol. 8, no. 2, pp. 95102, 1998.

[14] I. Bardhan, A. Bergier, E. Derman, C. Dosemblet, P. I. Knai, and Karasinski, "Valuing convertible bonds as derivatives," Goldman Sachs Quantitative Strategies Research Notes, 1993.

[15] D. Duffie and K. J. Singleton, "Modeling term structures of defaultable bonds," Review of Financial Studies, vol. 12, no. 4, pp. 687-720, 1999.

[16] A. Takahashi, T. Kobayashi, and N. Nakagawa, "Pricing convertible bonds with default risk," Journal of Fixed Income, vol. 11, no. 3, pp. 20-29, 2001.

[17] E. Ayache, P. A. Forsyth, and K. R. Vetzal, "The valuation of convertible bonds with credit risk," Journal of Derivatives, vol. 11, no. 1, pp. 9-29, 2003.

[18] D. R. Chambers and Q. Liu, "A tree model for pricing convertible bonds with equity, interest rate, and default risk," Journal of Derivatives, vol. 14, no. 4, pp. 25-46, 2007.

[19] K. M. Milanov, O. Kounchev, F. J. Fabozzi, Y. S. Kim, and S. T. Rachev, "A binomial-tree model for convertible bond pricing," The Journal of Fixed Income, vol. 22, no. 3, pp. 79-94, 2013.

[20] V. Naik, "Option valuation and hedging strategies with jumps in the volatility of asset returns," Journal of Finance, vol. 48, no. 5, pp. 1969-1984, 1993.
[21] J. Buffington and R. J. Elliot, "American options with regime switching," International Journal of Theoretical and Applied Finance, vol. 5, no. 5, pp. 497-514, 2002.

[22] P. Boyle and T. Draviam, "Pricing exotic options under regime switching," Insurance: Mathematics and Economics, vol. 40, no. 2, pp. 267-282, 2007.

[23] F. L. Yuen and H. Yang, "Option pricing with regime switching by trinomial tree method," Journal of Computational and Applied Mathematics, vol. 233, no. 8, pp. 1821-1833, 2010.

[24] T. K. Siu, H. Yang, and J. W. Lau, "Pricing currency options under two-factor Markov-modulated stochastic volatility models," Insurance: Mathematics and Economics, vol. 43, no. 3, pp. 295-302, 2008.

[25] S. Goutte, "Pricing and hedging in stochastic volatility regime switching models," Journal of Mathematical Finance, vol. 3, pp. 70-80, 2013.

[26] N. Song, Y. Jiao, W. K. Ching, T. K. Siu, and Z. Y. Wu, "A valuation model for perpetual convertible bonds with markov regime-switching models," International Journal of Pure and Applied Mathematics, vol. 53, no. 4, pp. 583-600, 2009.

[27] R. D. King, "The effect of convertible bond equity values on dilution and leverage," The Accounting Review, vol. 59, no. 3, pp. 419-431, 1984.

[28] P. P. Boyle, "A lattice frame work for option pricing with two state variables," Journal of Financial and Quantitative Analysis, vol. 23, no. 1, pp. 1-23, 1988. 


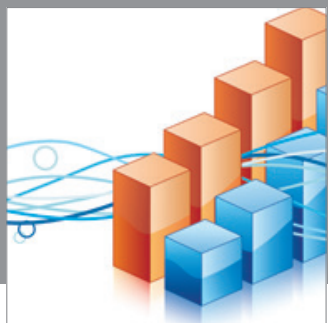

Advances in

Operations Research

mansans

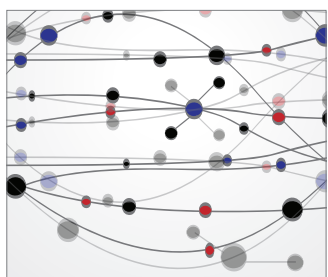

The Scientific World Journal
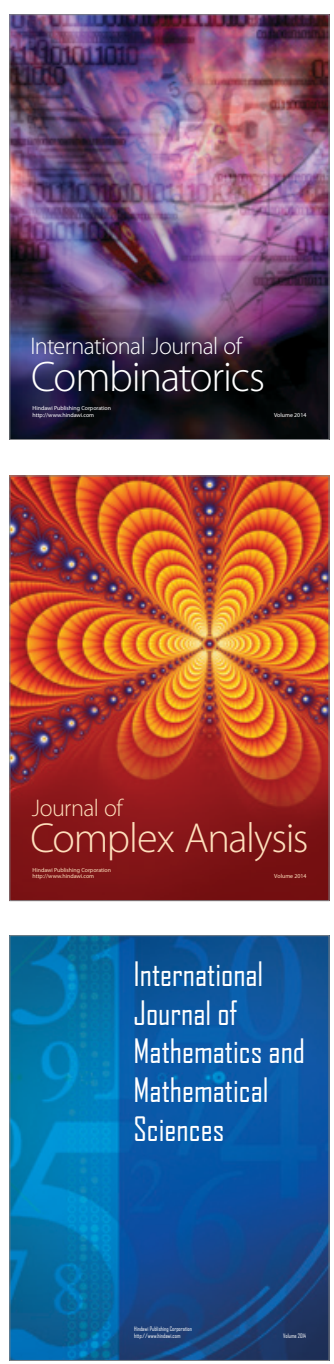
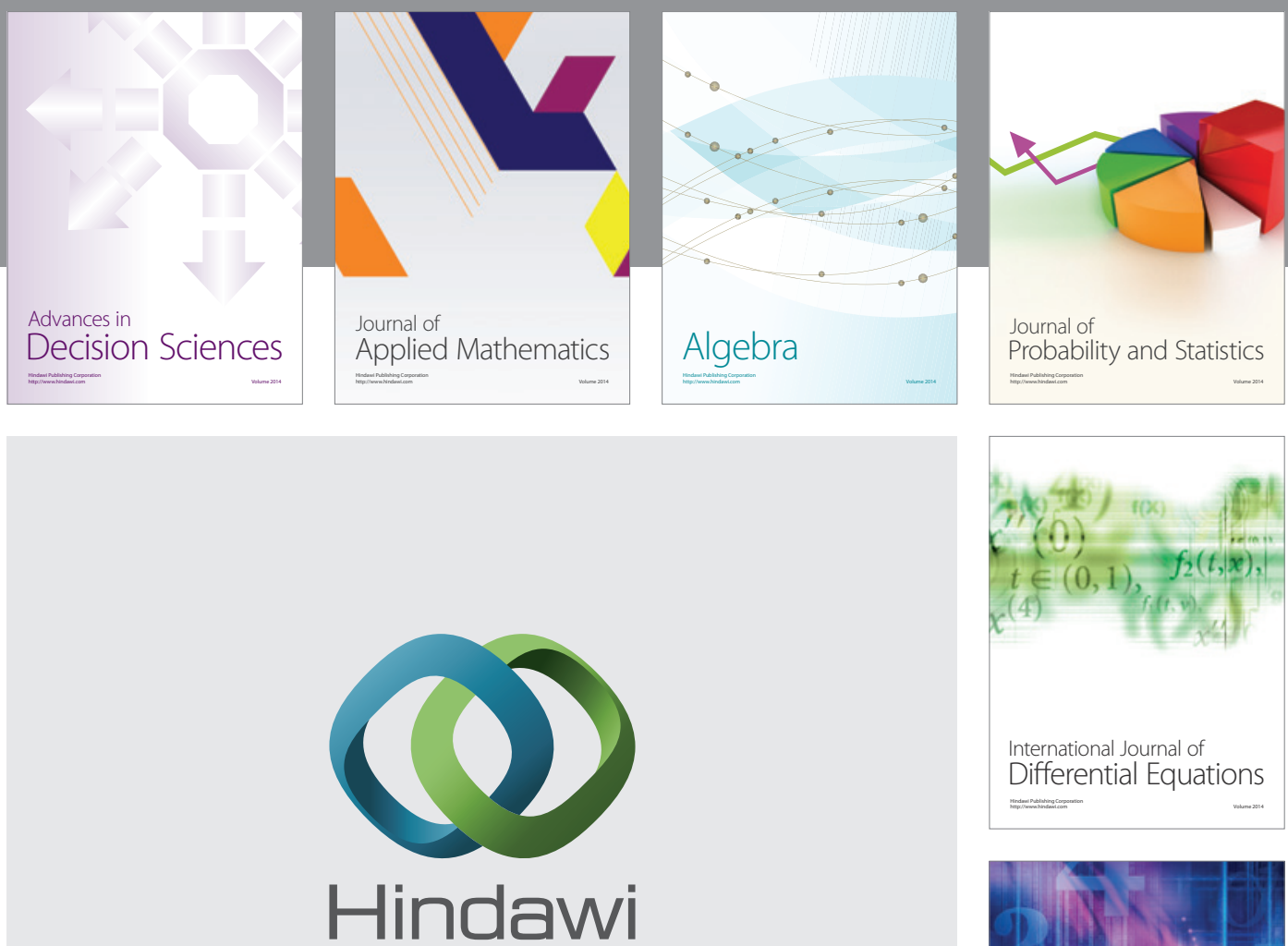

Submit your manuscripts at http://www.hindawi.com
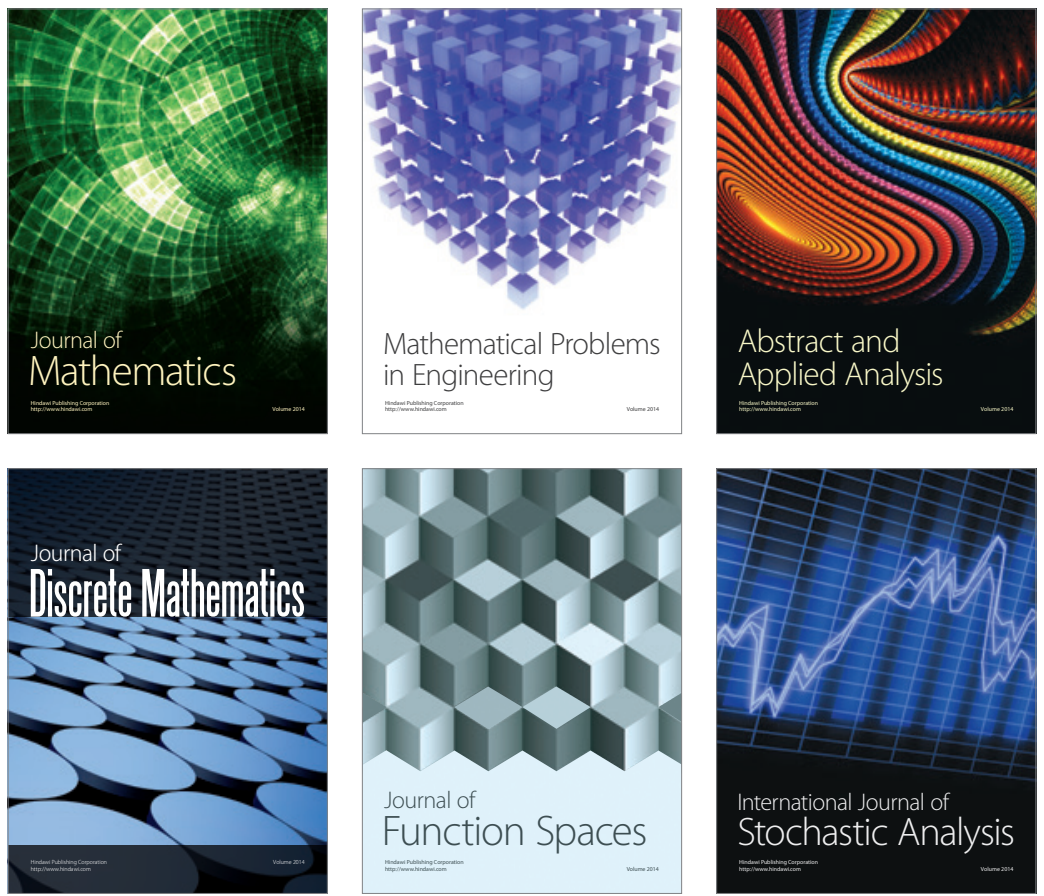

Journal of

Function Spaces

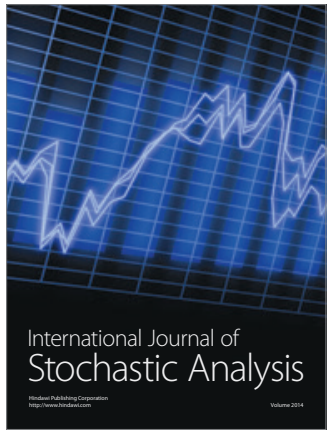

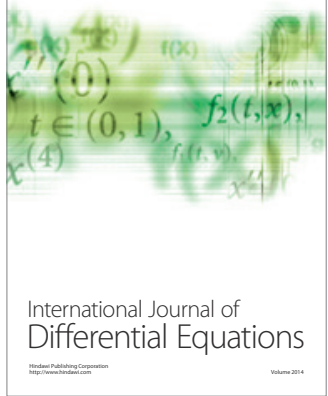
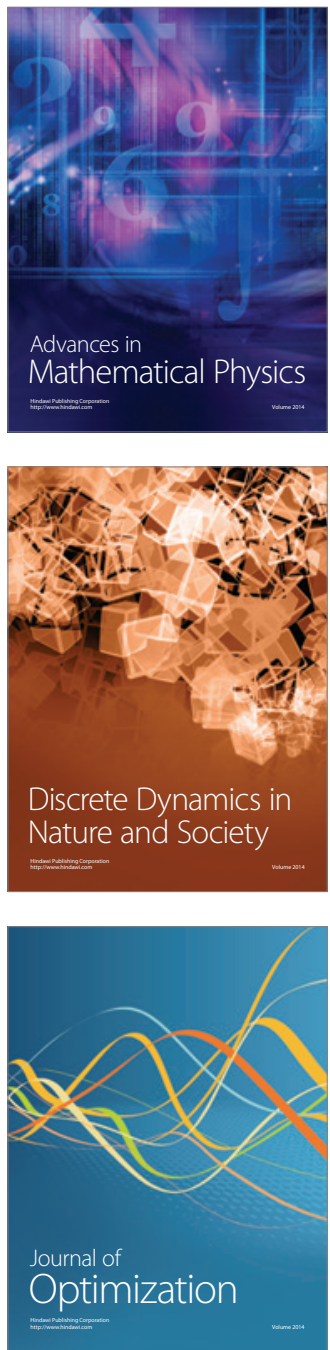